\title{
Baldermath: A Design-Based Research Approach to Developing a Game for Student Work Analysis
}

Three key features of high quality analysis of student work

1) Discussion is focused on student work.

2) Participants attend to the details in student work.

3) Each participant engages in making sense of student thinking.

Games can help teachers develop and practice important skills

Games as "practice spaces" for teaching - The complexities of teaching can be distilled into approximations of practice (Grossman et al, 2009). - Games allow individuals to take the "projective identity" of others (Gee, 2003)

Games can trigger empathy and perspective taking (Boltz et al, 2015).

Analyzing student work is a useful pedagogical tool, but challenging to learn and practice.

Background: Analyzing student work - Develops pedagogical content knowledge and ambitious practice (Windschitl, et al. 2011)

- Draws attention to details of student thinking in math classrooms (Kazemi \& Franke, 2003).

Can be an "alternate curriculum" for teacher education (Ball \& Cohen, 2009) $\rightarrow$ HOWEVER $\leftarrow$

- Analyzing student work requires facilitation and practice (Kazemi \& Franke, 2003)

Conversations often migrate away from student work towards students and instruction (Little, 2003).

- Preservice teachers often don't have access to student work, making practice challenging
Design Question:

How might we design a game to initiate high quality student work analysis?

BalderMath!

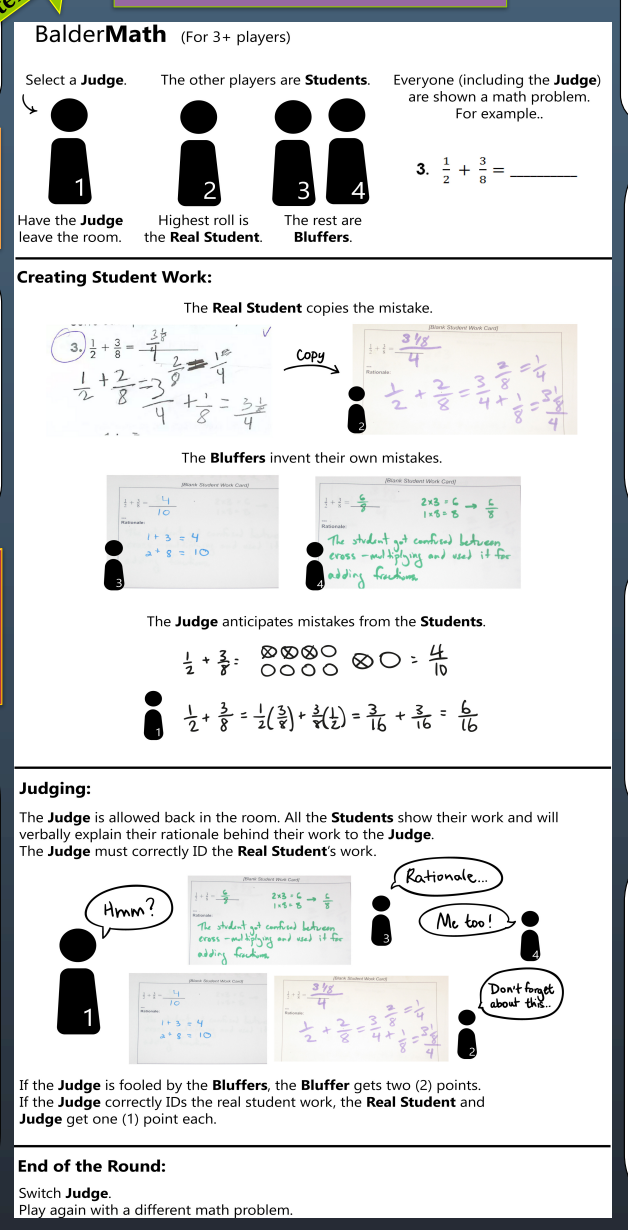

Research Question:

Can integrating student work analysis into a game help participants focus on, attend to details, and make sense of student work?

Method: Design-based research
Research learner needs, rapid prototypes, iterative revisions (Easterday et al 2014) Tested with in-service and preservice teachers over eight sessions in 9 months $(\mathrm{N}=30$ Data sources - analysis of game play discussion and debrief, written artifacts.

From evaulating to interpreting ......

From "...the students don't know how to add it to three- fourths properly......

To "And then I saw there was sort of a connection between the next two, comparing $2 / 5$ to $3 / 10 . .$.

Developing empathy for student perspectives

a critical piece of this, so it's not just the intellectual part of, "How do I understand kids thinking? Whe "What does it feel like to not know? What does it feel like to have your work misinterpreted?"

Game simulates aspects of teacher practice

..."Well and I felt like this is something that I would exactly do.... I go, "So tell me what you were thinking when you approached this." ...even kids that are right then have to explain their thinking and then they're like, "Wait, am I wrong?" "No, I wanted to hear you explain your thinking."

Preliminary Findings

During the game, participants focused on, attended to, and made sense of student work.

Participants moved from an evaluative view of student work as right or wrong to an

interpretive view as a source of information (Doerr, 2006).

Participants gained appreciation for students' perspectives.

$$
\text { Next steps }
$$

Testing with more participants/ integrating into courses

- Investigating effect on teaching practice

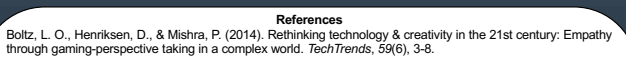

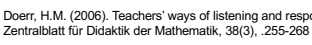

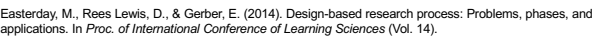

Gee, J. P. (2003), What vid
(CIE), (1), 20-20.

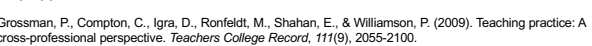

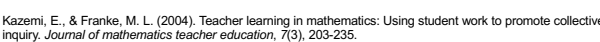

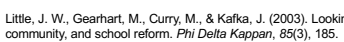

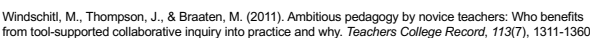

Do you want to use Baldermath with your preservice or inservice teachers? We are glad to help! tsl.mit.edu 